\title{
SENSITIVITY AND SPECIFICITY OF NEUTROPHIL COUNT, CRP, LEUKOCYTE COUNT AND USG ABDOMEN IN THE DIAGNOSIS OF ACUTE APPENDICITIS: A RETROSPECTIVE STUDY
}

\author{
P. Naresh Kumar' H. Ajith Kumar'2, P. Madhumitha ${ }^{3}$ \\ ${ }_{1}^{1}$ Associate Professor, Department of General Surgery, Sri Venkateshwaraa Medical College \& Research Centre, Ariyur, Pondicherry. \\ ${ }^{2}$ Assistant Professor, Department of General Surgery, Sri Venkateshwaraa Medical College \& Research Centre, Ariyur, Pondicherry. \\ 3 Junior Resident, Department of General Surgery, Sri Venkateshwaraa Medical College \& Research Centre, Ariyur, Pondicherry.
}

\section{ABSTRACT}

\section{BACKGROUND AND OBJECTIVES}

Acute appendicitis is the most common cause of acute surgical abdomen and appendicectomy is the most commonly done emergency surgery. Its diagnosis remains an enigmatic challenge, plagued by a high rate of negative explorations (15-30\%). There is no single reliable test with satisfactory sensitivity and specificity. The objective of the study was to evaluate role of few known and proven investigations for appendicitis like CRP, leukocyte count, Neutrophil count and Ultrasonography in diagnosing acute appendicitis and reducing the rate of negative appendicectomies. Also we wanted to study whether combining the investigations in same patient would improve the diagnostic accuracy.

\section{METHODS}

The present study was conducted in 100 patients who have been clinically diagnosed of having Acute Appendicitis and posted for emergency appendicectomy in General Surgery Department of Sri Venkateshwaraa Medical College and Hospital, Pondicherry, during the period from 1st May 2015 to 31st December 2015. Preoperatively blood for CRP, WBC count, Neutrophil count and USG abdomen were done. All appendicectomy specimens were subjected to histopathological examination postoperatively, which was taken as gold standard. Results of all the four investigations were correlated with HPE reports to evaluate their role in diagnosis of acute appendicitis.

\section{RESULTS}

In present study, CRP has highest sensitivity and specificity $(90 \%, 80 \%)$ followed by USG $(87.5 \%, 90 \%)$, WBC count $(78.75 \%$, $80 \%)$ and Neutrophil count (77.5\%, 80\%). Combining CRP and WBC count increases the sensitivity and specificity of the tests $(96.25 \%, 80 \%)$. When all the four tests are combined (Either/all) the sensitivity, specificity, positive predictive value and predictive value of negative test increases significantly $(100 \%, 80 \%, 95.23 \%, 100 \%$ respectively). It was observed that when all the four tests were negative appendicitis could be safely ruled out and surgery can be deferred in these patients. It would reduce the rate of negative appendicectomies.

\section{INTERPRETATIONS AND CONCLUSIONS}

CRP contains important diagnostic information and hence should always be included in the diagnostic workup of acute appendicitis. The sensitivity of WBC count and Neutrophil count is low individually, but when combined with CRP the sensitivi ty and specificity increases. Ultrasonography is useful in establishing alternative diagnoses, but its availability and cost-effectiveness should be taken into account. Combining all four investigations significantly increases the diagnostic accuracy. Also when all four tests are negative acute appendicitis is very unlikely and surgery can be safely deferred in these patients thereby reducing the negative appendicectomy rates. We continue to stress that history and clinical examination by a skilled surgeon still remains indispensable in diagnosing acute appendicitis and its importance cannot be undermined. The investigations can be used to complement a Surgeon's clinical diagnosis and not replace it.

\section{KEYWORDS}

CRP; Acute Appendicitis; WBC Count; Neutrophil Count; USG; Histopathological Report.

HOW TO CITE THIS ARTICLE: Kumar PN, Kumar HA, Madhumitha P. Sensitivity and specificity of neutrophil count, CRP, leukocyte count and USG abdomen in the diagnosis of acute appendicitis: a retrospective study. J. Evolution Med. Dent. Sci. 2016;5(14): 634-636, DOI: $10.14260 /$ jemds/2016/145

\section{INTRODUCTION}

\section{Need for the study}

Acute appendicitis is one of the most common cause of right iliac fossa pain and one of the most common cause of surgical emergencies.

\section{Financial or Other, Competing Interest: None.}

Submission 31-12-2015, Peer Review 29-01-2016,

Acceptance 05-02-2016, Published 17-02-2016.

Corresponding Author:

Dr. P. Naresh Kumar,

SVMC \& RC, Ariyur, Pondicherry.

E-mail:drnk.2011@gmail.com

DOI: $10.14260 /$ jemds/2016/145
Its diagnosis is established by surgeon's clinical impression depending on presenting history, clinical evaluation and laboratory tests. Acute appendicitis with protean manifestations may simulate almost any other acute abdominal conditions and in turn may be mimicked by a variety of conditions.

Appendicectomy for suspected acute appendicitis is a common procedure. The rate of normal appendices unnecessarily removed remains high (15\%-30\%) despite several techniques. On one hand, a normal appendix at appendicectomy represents a misdiagnosis, on the other hand a delayed diagnosis of appendicitis may lead to perforation and peritonitis. 
Negative appendicectomies are one of the burdens facing not only the general surgeon but also the patient himself and the society as a whole, since appendicectomy as any other surgery results in socio-economic impacts in form of loss of working days and declined productivity in addition to complications arising out of operative trauma.

To conclude as acute appendicitis may simulate many other acute abdominal conditions/illnesses and despite intensive clinical research and discussion the diagnosis of acute appendicitis still remains a challenge and the exact diagnosis is important for proper management.

It has long been recognised that white cell count is elevated in acute appendicitis and is of significant value in diagnosis. CRP is one of the acute phase reactants that may rise in concentration because of the synthesis by hepatocytes during acute phase response to inflammation. CRP is not disease specific, but it may offer valuable diagnostic information about presence of acute infection with concomitant evaluation of patient history and physical examination.

This study aims at comparing the few known and proven investigations for appendicitis like CRP, Leukocyte count, Neutrophil count and Ultrasonography. Comparing how specific and sensitive each one is, which is best and has maximum positive predictive value. This would be done by comparing it with HPE report. The need for study is to find out, which is most accurate and sensitive investigation to improve diagnosis of appendicitis and decision making and hence decrease negative and unnecessary appendicectomies.

\section{Review of Literature}

Individual lifetime risk of appendicectomy is $8.6 \%$ and $6.7 \%$ among males and females respectively. ${ }^{1} \mathrm{~A}$ decision to operate based on a clinical suspicion alone can lead to the removal of normal appendix in $15-30 \%$ of cases. ${ }^{1}$

The average leukocyte count is $15,000 / \mathrm{mm} 3$ and $90 \%$ of patients have counts over $10,000 / \mathrm{mm} 3$. In three-fourths of patients, the differential white count shows more than $75 \%$ neutrophils. ${ }^{2}$

Ultrasonography increases the diagnostic accuracy in patients with suspected acute appendicitis. ${ }^{3}$ Most studies of graded compression ultrasound demonstrate a sensitivity of more than $85 \%$ and a specificity of more than $90 \%{ }^{4}$

A normal pre-operative serum CRP measurement in patients with suspected acute appendicitis is most likely associated with a normal appendix. Deferring surgery in this group of patients would probably reduce the rate of unnecessary appendicectomies. ${ }^{5}$

However, if the C-reactive protein level in blood drawn 12 hours after the onset of symptoms is less than $2.5 \mathrm{mg} / \mathrm{dL}$, acute appendicitis can be excluded. ${ }^{6}$ The triple test (WBC count, CRP and Neutrophil percentage) is recommended as a help in reducing the significant rate of negative laparotomies in patients suspected of having acute appendicitis. ${ }^{7}$

We found that elevated serum CRP levels support surgeon's clinical diagnosis. We recommend CRP measurement as a routine laboratory test in patients with suspected diagnosis of acute appendicitis. ${ }^{8}$

Laboratory tests of the white cell count, Neutrophil count and C-reactive protein are more effective in supporting a clinical diagnosis of acute appendicitis in patients with typical clinical features than in excluding the diagnosis. ${ }^{9}$
In conclusion, patients with normal results in all three tests are highly unlikely to have acute appendicitis and should be evaluated with extra caution before surgery. ${ }^{10}$ Although all clinical and laboratory variables are weak discriminators, individually they achieve a high discriminatory power when combined. 11

\section{Objectives of the Study}

1. To determine specificity, sensitivity, predictive value of positive test and predictive value of negative test in diagnosis of acute appendicitis.

2. To individually correlate CRP/Leukocyte count/Neutrophil count/USG in case of clinical acute appendicitis by HPE correlation.

3. To interpret the efficacy of combining all the investigation in same patients.

4. To determine which of them is best and most costeffective.

5. To interpret how these investigations can be used effectively to improve the diagnosis and decision making of acute appendicitis and hence reduce negative appendicectomies.

\section{MATERIALS AND METHODS}

\section{Source of Data}

Patients who have been clinically diagnosed of having Acute Appendicitis and posted for emergency appendicectomy in General Surgery Department of SVMCH, Pondicherry during the period from 1st May 2015 to 31st December 2015.

\section{Method of Collecting Data}

Sample Size: 100 cases of acute appendicitis.

Sampling Method: Simple random sampling.

\section{Inclusion Criteria}

All patients above the age of 15 yrs. diagnosed clinically to have Acute Appendicitis and subjected to Appendicectomy in General Surgery Department of SVMCH, Pondicherry.

\section{Exclusion Criteria}

1. Patient with $\mathrm{h} /$ o recurrent pain in right iliac fossa.

2. Patient with appendicular mass/peritonitis.

3. Concomitant conditions when CRP/Leukocyte count/Neutrophil count is elevated.

\section{Investigations}

1. C-reactive protein

2. Neutrophil count.

3. Leukocyte count.

4. Ultrasonography.

\section{RESULTS}

In present study, CRP has highest sensitivity and specificity (90\%, 80\%) followed by USG $(87.5 \%, 90 \%)$, WBC count (78.75\%, 80\%) and Neutrophil count (77.5\%, 80\%). Combining CRP and WBC count increases the sensitivity and specificity of the tests $(96.25 \%, 80 \%)$.

When all the four tests are combined (Either/all) the sensitivity, specificity, positive predictive value and predictive value of negative test increases significantly (100\%, 80\%, $95.23 \%, 100 \%$ respectively).

It was observed that when all the four tests were negative, appendicitis could be safely ruled out and surgery 
can be deferred in these patients. It would reduce the rate of negative appendicectomies.

\section{INTERPRETATIONS AND CONCLUSIONS}

CRP contains important diagnostic information and hence should always be included in the diagnostic workup of acute appendicitis. The sensitivity of WBC count and Neutrophil count is low individually, but when combined with CRP the sensitivity and specificity increases.

Ultrasonography is useful in establishing alternative diagnoses, but its availability and cost-effectiveness should be taken into account. Combining all four investigations significantly increases the diagnostic accuracy. Also when all four tests are negative, acute appendicitis is very unlikely and surgery can be safely deferred in these patients, thereby reducing the negative appendicectomy rates.

We continue to stress that history and clinical examination by a skilled surgeon still remains indispensable in diagnosing acute appendicitis and its importance cannot be undermined. The investigations can be used to complement a surgeon's clinical diagnosis and not replace it.

\section{LIST OF ABBREVIATIONS}

CRP-C Reactive Protein

CT-Computer Tomography

HPE-Histopathological Examination

PID-Pelvic Inflammatory Disease

RLQ-Right Lower Quadrant

WBC-White Blood Count

\section{REFERENCES}

1. Norman S Williams, Christopher JK Bullstrode, P Ronan O'Connell. The vermiform appendix. In: Bailey and Love's Short Practice of Surgery, 25th ed. London: Hodder Arnold; 2008. p 1205-11.

2. Lawrence $W$ Way. Appendix. In: Current surgical diagnosis and treatment. Gerard M Doherty 12th ed. New Delhi: McGraw-Hill companies; 2006. p 649.
3. Dr M Galindo Gallego, Fadrique B, Nieto MA. Evaluation of ultrasonography and clinical diagnostic scoring in suspected appendicitis. British Journal of Surgery, Volume 85, Issue 1, Pages 37-40.

4. Kevin P Lally, Charles S Cox. Appendix. In: Sabiston textbook of surgery, the biological basis of surgery. Townsend M Courtney, Beauchamp R Daniel, Evers B Mark, Mattox L Kenneth (eds). Philadelphia: Elsevier 2005; p 1384.

5. Asfar S, Safar H, Khoursheed M, et al. Would measurement of C-reactive protein reduce the rate of negative exploration for acute appendicitis? JR Coll Surg Edinb. 45, February 2000;21-4.

6. Eugene Albu, Barnett M Miller, Young Choi, et al. Diagnostic value of $\mathrm{C}$-reactive protein in acute appendicitis. Diseases of the colon and rectum. Publisher Springer New York, January 1994, Volume 37, Number 1.

7. Svend Dueholm MD, Per Bagi MD, Margreta Bud MD. Laboratory aid in the diagnosis of acute appendicitis. A blinded, prospective trial concerning diagnostic value of leukocyte count, neutrophil differential count and Creactive protein. Dis Colon Rectum 1989;32:855-859.

8. Emin Gurleyik, Gunay Gurleyik and Selcuk Unalmiser. Accuracy of serum C-reactive protein measurements in diagnosis of acute appendicitis compared with surgeon's clinical impression. Journal Diseases of the Colon and Rectum, Springer, December 1995, New York Issue, Volume 38, Number 12, p 1270-1274.

9. Birchley D. Patients with clinical acute appendicitis should have preoperative full blood count and C-reactive protein assays. Ann R Coll Surg Engl 2006 January; 88(1):27-32.

10. Yang Horng-Ren, Wang Yu-Chun, Ping-Kuei, et al. Role of leukocyte count, neutrophil percentage and C-reactive protein in the diagnosis of acute appendicitis in the elderly. The American Surgeon, Volume 71, Number 4, April 2005, p. 344-347(4).

11. Andersson REB. Meta-analysis of the clinical and laboratory diagnosis of appendicitis. British Journal of Surgery, 2003, Volume 91, Issue 1, Pages 28-37. 